\title{
KEPERCAYAAN MASYARAKAT KARO TERHADAP MAKAM KERAMAT SIBAYAK LINGGA DI BUKIT NDAHOLI DESA PERBESI KECAMATAN TIGABINANGA KABUPATEN KARO
}

\author{
Krisna Abadi Ginting \\ Alumni Program Studi Antropologi, Fakultas Ilmu Sosial, Universitas Negeri Medan \\ krisna.abadi@gmail.com
}

\begin{abstract}
ABSTRAK
Raja Sibayak Lingga adalah seorang raja yang memiliki kekuatan sakti pada jaman dahulu kala, masyarakat Desa Perbesi menyembah dan memberikan sesajen kepada makam yang berada di bukit Ndaholi tersebut karena dianggap sakral dan memiliki kekuatan yang sakti. Tujuan penulis meneliti makam kramat raja Sibayak Lingga yang berada di Desa Perbesi yakni mengetahui proses ritual yang dilakukan oleh masyarakat pada makam Sibayak Lingga di bukit Ndaholi. Tujuan utama dari penelitian ini ialah mengetahui latarbelakang masyarakat Karo mengadakan ritual pada makam keramat Sibayak Lingga di bukit Ndaholi Desa Perbesi. Metode yang digunakan oleh penulis dalam penelitian ini ialah penelitian yang bersifat kualitatif dengan pendekatan deskriptif. Data diperoleh dari teknik observasi, wawancara dengan beberapa informan, dokumentasi, studi kepustakaan. Penelitian dilakukan pada bulan Januari 2017 sampai bulan februari 2017 tempat Desa Perbesi Kecamatan Tigabinanga Kabupaten Karo. Berdasarkan hasil penelitian masyarakat Perbesi menyembah dan membuat ritual kepada makam Sibayak Lingga dikarenakan sejarah dari Sibayak Lingga dan dari cerita masyarakat pada jaman dahulu. Selain itu masyarakat juga melihat bahwa Raja Sibayak Lingga dulunya memiliki kesaktian, maka dari itu sebagian dari masyarakat Desa Perbesi meyakini bahwasanya makam tersebut dapat memberikan suatu keinginan seperti meminta jodoh, meminta nomor (togel), menyembuhkan penyakit, dan membuang segala kesialan dengan berharap rejeki pun melimpah.
\end{abstract}

Kata Kunci: Ritual, Makam Keramat, Sibayak Lingga 


\section{PENDAHULUAN}

Masyarakat Karo pada umumnya menganut agama Kristen, Islam dan Hindu. Setelah masyarakat Karo mulai mengenal agama, maka muncul larangan-larangan dari agama tersebut untuk berhenti menganut ajaran yang tak sejalan dengan ajaran agama. Namun masih ada beberapa dari Masyarakat Karo yang masih percaya kepada roh nenek moyang dan hal gaib lainnya. Salah satu kepercayaan yang diyakini masyarakat Karo adalah penyembahan terhadap makam-makam para raja ataupun yang bersifat mistis.

Pada suatu wilayah di kabupaten Karo, yakni bukit Ndaholi diyakini Masyarakat Karo sebagai salah satu tempat yang sakral atau keramat. Letaknya di bukit Ndaholi Desa Perbesi, diatas bukit tersebut terdapat sebuah makam yang diyakini sebagai makam raja yang bernama Sibayak Lingga. Menurut dari informasi yang penulis dapatkan dari Masyarakat Perbesi, beliau adalah raja dari keturunan marga Lingga yang dimakamkan di atas bukit Ndaholi. Bagi masyarakat sendiri makam raja tersebut sangat disakralkan, dan penulisjuga pernah melihat ada berupa sesajen maupun persembahanpersembahan yang diletakkan di atas makam raja tersebut.

Beberapa pantangan diterapkan di atas bukit tersebut, diantaranya tidak boleh membunuh hewan yang berada di atas makam tersebut, mengucap kata-kata kotor, berzinah dan lain-lain. Menurut mitos yang ada, pernah ada sepasang kekasih yang membunuh ular di atas bukit Ndaholi tersebut. Setelah membunuh ular yang berada di nukit tersebut keesokan harinya sepasang kekasih tersebut meninggal dunia tanpa ada gejala-gejala penyakit ataupun semacamnya. Menurut dari cerita yang penuli dengar dari masyarakat, peristiwa meninggalnya sepasang kekasih tersebut diyakini akibat melanggar pantangan pada sewaktu berada di atas bukit tersebut. Selain adanya pantangan-pantangan yang ada masyarakat Perbesi juga percaya jika kita berada di atas bukit tersebut dan berdoa, masyarakat juga percaya akan diberikannya hujan maupun jodoh bagi mreka.

\section{METODE PENELITIAN}

Berdasarkan dari judul yakni Kepercayaan Masyarakat terhadap Tempat Keramat Pada Makam Sibayak Lingga di Bukit Ndaholi Desa Perbesi Kecamatan Tigabinanga Kabupaten Karo penelitian ini menggunakan metode peneitian deskriptif kualitatif. Dalam metode deskriptif, penulis bisa saja membandingkan fenomena-fenomena tertentu sehingga merupakan suatu studi komparatif. Adakalanya penulismengadakan klasifikasi, serta penelitian terhadap fenomena-fenomena dengan menetapkan suatu standart atau norma tertentu

Penulis menggunakan penelitian lapangan (field research) dengan bentuk observasi non partisipasi (non partisipan observer). Data yang diperoleh dari penelitian lapangan di Desa Perbesi bukit Ndaholi. Selain field research, penulisjuga melakukan studi pustaka (library research) untuk menambah data yang relevan dengan penelitian yang dilakukan, guna menunjang fakta yang sesuai dengan keadaan yang ada di lapangan. Data-data yang didapatkan berupa buku-buku, jurnal, artikel, dan tulisan-tulisan ilmiah lainnya yang juga memuat tentang informasi-informasi yang dibutuhkan dalam penelitian.

Adapun lokasi penelitian ini adalah di Desa Perbesi Kecamata Tigabinanga, Kabupaten Karo, penulisbertujuan menepatkan lokasi di Desa Perbesi karena menurut pandangan penulis, di Desa tersebut terdapat adanya permasalahan yang ingin diteliti oleh penulis.

Subjek penelitian adalah orang yang dapat memberikan informasi-informasi utama yang dibutuhkan dalam penelitian. Dalam penelitian ini yang menjadi informan kuncinya adalah keturunan dari raja Sibayak Lingga, tokoh adat yang tau bagaimana sejarah dan mitos mengenai makam Sibayak Lingga, Kepala Desa, masyarakat Karo yang tinggal di Desa Perbesi,. Informan tambahan ini adalah mereka yang dapat menambahkan berbagai informasi terkait dengan permasalahan yang diteliti oleh penulis dan tidak terlepas dari informan kunci yang sudah terlebih dahulu memberikan informasi.

Objek penelitian adalah permasalahan yang diteliti. Objek dari penelitian ini adalah makam sibayak Lingga yang berada dibukit Ndaholi Desa Perbesi kecamatan Tigabinanga kabupaten Karo.

\section{Sejarah Sibayak Lingga}

Sibayak Lingga Raja Senina merupakan putra pertama dari Raja Sibayak Lingga Raja Natang dan beliau adalah pewaris resmi kerajaan Lingga yang berada di Desa Perbesi. Sibayak Lingga sendiri terkenal sakti, ramah, dan sangat disegani masyarakat pada era pemerintahannya. Sibayak Lingga Raja Senina sendiri memiliki istri atau dalam bahasa Karo (kemberahen) sebanyak 8 orang dan dikaruniai 10 orang anak dari ke8 istrinya tersebut. Beliau memilik 5 putra dan 5 putri yakni:

Sebelum Raja Sibayak Lingga wafat ataupun meninggal, Raja Sibayak Lingga berpesan ke pada Kalimbubu, Anak beru, dan Sembuyaknya (Saudara terdekat Raja Sibayak Lingga). Apabila beliau meninggal dunia Raja Sibayak Lingga berkeinginan atau berpesan supaya ia disemayamkan di uruk Ndaholi Tambak Malim ( uruk Ndaholi) Desa Perbesi. Maksut dan tujuan Raja Sibayak Lingga Raja Senina memilih tempat tersebut agar Kalimbubu Sebayang ( kluarga dari istri Raja Sibayak Lingga yang bermarga br.Sebayang) dapat berjiarah setiap saat dan dapat memandang kuburan ayahnya yang tercinta Sibayak Lingga Raja Natang yang berada di Desa Lingga yang dikuburkan di uruk Mbelin Lingga ( bukit Mbelin Lingga) dekat kota Kabanjahe.

Sibayak Lingga atau Raja Lingga meninggal dunia di Desa Lingga, maka dengan kata mufakat Kalimbubu, Anak beru, dan Sembuyak (saudara terdekat Raja Sibayak Lingga Raja Senina), maka Sibayak Lingga Raja Senina diantarkan oleh berpuluh-puluh ribu penduduk Tanah Karo dan beribu-ribu barisan kuda kerajaan Karo pada saat itu ikut mengantarkan Raja Sibayak Lingga Raja Senina keatas buki Ndaholi Desa Perbesi (uruk Ndaholi 
Tambak Malim kuta Perbesi). Dengan kebesaran adat karo membuat pesta selama satu minggu lamanya (erkata gendang seh ngasa 1 minggu). Dan beliau juga ingin makamnya dibuat lambang dari kebesaran suku Gayo dikarenakan beliau tau asal dari marga Lingga berasal dari suku Gayo.

Raja Sibayak Lingga dikenal sangat jujur dan sakti, pada saat ngangkat tulan-tulan (mengangkat tulang-tulang) maka tabu bah (batok kepala) Raja Sibayak Lingga pada saat itu diangkat dan disimpan di rumah kurung manik sampai sekarang. Batok kepala tersebut disusun agar marga Lingga tetap mempunyai bukti sebagai keturunan Sibayak Lingga.

\section{Alasan Masyarakat Desa Perbesi Menyembah Makam Sibayak Lingga}

Berdasarkan hasil wawancara penulis dengan narasumber tersebut dapat penulis simpulkan bahwasanya, alasan masyarakat Desa Perbesi sendiri membuat ritual terhadap makam Raja Sibayak Lingga sendiri adalah karena masyarakat menganganggap makam Raja Sibayak Lingga adalah seorang Raja dan menjadi sosok nenek moyang mereka. Selain itu dibuatnya ritual seperti pelepasan ayam yang berbuluh putih diatas bukit Ndaholi agar kejadian-kejadian mistis maupun kesialan tidak terjadi kepada masyarakat Desa Perbesi. Selain itu Masyarakat Desa Perbesi sendiri sudah menganggap Raja Sibayak Lingga sebagai salah satu nenek moyang mereka dan merupakan Raja marga Lingga dari Desa Lingga Kabupaten Karo yang berada didekat Kabanjahe. Selain Raja Sibayak Lingga sendiri adalah seorang Raja alasan mengapa setiap tahunnya mreka membuat ritual terhadap makam Raja Sibayak Lingga tersebut adalah dikarenakan dulunya seringkali bukit tersebut ermuat (memakan tumbal).

Berdasarkan crita ataupun mitos pada jaman dahulunya pernah ada seorang pria membunuh binatang diatas bukit Ndaholi. Selain kejadian pria tersebut sebelumnya juga banyak masyarakat yang meninggal tanpa tau sebab dan mengenai penyakit yang diderita oleh korban dari bukit uruk Ndaholi. Binatang tersebut adalah Wili (Babi hutan), selain babi hutan hewan seperti Nipe (ular) juga disarankan untuk tidak membunuh binatang terebut jika kita menjempuai binatang di atas bukit Ndaholi. Babi hutan dibunuh prita tersebut tepat diatas bukit Ndaholi dengan alasan menjadi gulenna (makanan) untuk di rumahnya.

\section{Panglima Raja Sibayak Lingga}

Berdasarkan hasil wawancara penulis dengan narasumber disimpulkan bahwa panglima diyakini masyarakat desa Perbesi adalah makam panglima Raja Sibayak Lingga adalah seorang tangan kanan ataupun orang yang paling dipercaya oleh Raja Sibyak Lingga dan slalu setia mengikuti kemanapun Raja Sibayak Lingga berada. Menurut crita dari kakek nenek kami pada jaman dahulu makam panglima Raja Sibayak Lingga tersebut ingin dimakamkan berada dekat disebelah makam Raja Sibayak Lingga, orang dulu menceritakan alasan dari panglima Raja Sibayak Lingga dapat selalu menjaganya selamalamanya. Dan kenapa makam tersebut berada tepat ditenga-tengah pohon bambu. Dengan adanya makam panglima raja Sibayak Lingga yang berdekata dengan Raja Sibayak Lingga masyarakat desa Perbesi meyakini jika kita melakukan ritual terhadap makam Sibayak Lingga kita harus menghorati penjaga dari makam Sibayak Lingga.

Selain itu makam panglima tersebut juga keramat dikarenakan letak dari makam tersebut dikelilingi oleh pohon bambu yang diyakini masyarat Dulunya masyarakat Desa Perbesi memakamkan beliau diatas bukit Ndaholi dengan mengabulkan permintaan dari panglima Raja Sibayak Lingga dan menginginkan diatas makamnya ditancapkan sebuah ukat (sendok nasi yang terbuat dari pohon bambu) dan pedang keris. Masyarakat dulu percaya bahwa pohon bambu yang melingkari makam tersebut adalah ukat (sendok nasi yang terbuat dari pohon bambu) yang ditancapkan berda diatas makamnya.

\section{Ngamburi Lau Simalem-malem (Memberikan Air Penyejuk)}

Ngamburi lau simalem-malem (Memberikan Air penyejuk) diberikan kepada makam pada hari tertentu yang dilakukan oleh keluarga ataupun keturunan langsung dari orang yang telah meninggal. Ngamburi lau simalem-malem biasanya dilakukan oleh keluarka pada pagi hari. Dari hasil wawancara penulis dengan informan dapat disimpulkan bahwa orang yang melakukan ritual ngamburi lau simalem-malem bertujuan untuk menghindai seseorang dari marabahaya baik yang dilakukan langsung maupun tidak langsung atau yang lebih dikenal sebagai santet. Selain itu keluarga juga dapat mengsucikan diri dilindungi maupun mengobati rasa kerinduan terhadap leluhur mereka.

\section{Erpangir (Membasuhi Diri Dengan Ramuan-Ramuan Tradisional)}

Berdasarkan hasil wawancara penulis dengan informan disimpulkan bahwa masyarakat Perbesi percaya akan adanya kekuatan yang dimiliki oleh Sibayak Lingga dengan semasa hidupnya yang dipercaya oleh masyarakat memiliki kekuatan sakti. Dengan kita mengikuti aturan dalam melakukan ritual tersebut masyarakat percaya bisa mendapatkan apa yang dikehendaki oleh masyarakat sepertihalnya menghindari suatu malapetaka, menyembuhkan suatu penyakit, mendapatkan jodoh, mendapatkan keberuntungan, dan memperoleh kedudukan yang baik. Adapaun tahap-tahap mengadakan ritual tersebut pertama kiita mengambil air yang berada dikaki bukit Ndaholi dan menyaipkan bahan-bahan seperti:n buah jeruk purut, Mangkuk, Air yang secukupnyaKemangi, Kemenyan

Adapun cara-cara dalam ritual ini terbilang sangat rumit karena hanya seorang dengan bantuan seorang guru (dukun) atau berilmulah yang dapat melakukan ritual tersebut. Disamping itu banyak mantra-mantra yang 
hanya dimengerti oleh mereka yang memang mengenal ataupun sering melakukan erpangir tersebut.

\section{Mulahken Manuk Mbentar (Melepas Ayang Berbulu Putih)}

Mulahken manuk mbentar (melepas ayam berbulu putih) dilakukan pada masyarakat Desa Perbesi dengan alasan agar masyarakat Desa Perbesi dapat terhindari dari bahaya dari hasil wawancara dengan informan ibu E. Sinulingga dengan ibu A. Sebayang mereka mengatakan bahwa:

Berdasaran dari hasil wawancara penulis dengan informan penulis menyimpulkan bahwasanya ritual yang dilakukan oleh masyarakat Desa Perbesi adalah salah satu tradisi yang dilakukan setiaptahunnya didalam Desa tersebut. Tradisi yang dilakukan oleh masyaraat Desa Perbesi adalah salah satu bentuk tradisi yang dilakukan untuk mengingatkan kepada masyarakat Desa Perbesi sendiri kepada nenek moyang mreka. Selain itu Ritual mulahken manuk mbentar masi dibuat sampai sekarang tepatnya pada pesta tahunan yang diadakan di Desa Perbesi biasanya pada bulan 6. Biasanya harinya ditentukan oleh guru mbelin, sebelum ritual mulahken manuk mbentar dilakukan guru mbelin melihat kalender Karo dan mencari hari yang tepat dalam melaksanakan ritual. Setelah ritual dilaksanakan barulah guru mbelin dapat menentukan hari dan tanggal untuk mengadakan pesta tahunan.

Masyarakat Desa Perbesi melakukan ritual mulahken manuk mbentar dengan alasan cerita dari orangtua darijaman dulu yang mengatakan seringkali dulunya masyarakat Desa mengalami kesialan dan terkena penyakit yang tidak diketahui. Dari banyaknya kejadian yang menimpa masyarakat Desa Perbesi maka guru mbelin (dukun) disuruh untuk melihat keatas bukit dan berkomunikasi dengan makam Sibayak Lingga. Kemudian setelah guru mbelin turun dan menyarankan masyarakat agar mengadakan ritual mulahken manuk mbentar setiap tahunya di atas bukit Ndaholi.

\section{Pandangan Masyarakat Karo Desa Perbes}

Menurut penulis kegiatan ritual yang dilakukan masyarakat Desa perbesi adalah salah satu wujud kepedulian mereka terhadap makam Sibayak Lingga. Selain sebagai wujud kepedulian masyarakat perbesi ingin tradisi yang telah dibuat untuk makam Sibayak Lingga tidak terputus dan terus berlangsung setiap tahunnya. Ziarah yang dilakukan oleh masyarakat Perbesi adalah salah satu wujud membersihkan diri dan membuang segala kesialan dengan mengharapkan keberuntungan.

\section{Pandangan Masyarakat Perbesi Dengan Masuknya Agama}

Menurut penulis dengan masuknya agama yang masuk kedalam Desa Perbesi sangat berpengaru dalam tradisi-tradisi ritual yang berlangsung setiap tahunnya dan keseharian mereka terhadap Sibayak Lingga. Karena ada beberapa masyarakat tidak mengikuti lagi ritual-ritual yang dibuat pada makam Sibayak Lingga tersebut. Selain itu banyak dari ajaran agama yang bertentangan juga dengan beberapa tradisi yang dibuat oleh masyarakat pada umumnya. Selain itu Masuknya agama memang sangat mempengaruhi tradisi yang dilakukan masyarakat Desa Perbesi seperti ritual erpangir. Biasanya ritual pangir dilakukan oleh masyarakat Desa Perbesi atau sebagian dari warga Desa Perbesi dilakukan secara diamdiam dan dilakukan pada pagi hari untuk menghindari tuduhan-tuduhan yang tidak mengenakkan. Selain itu ritual ngembahken manuk mbentar juga dianggap oleh beberapa masyarakat disini tidak ikut serta lagi mengadakan ritual tersebut dikarnakan mungkin bertentangan dengan agama yang dianut oleh mereka.Walaupun ada beberapa masyarakat Perbesi yang tidak ikut serta dalam ritual ini masyarakat perbesi masi banyak yang melakukan kegiatan ritual tersebut baik yang menganggap menghindari kesialan dan menganggapnya itu sebagai tradisi.

\section{PENUTUP}

Berdasarkan penelitian yang sudah dilakukan oleh penulis dengan menggunakan jenis penelitian yang bersifat kualitatif dengan pendekatan deskriptif dan didukung oleh hasil observasi dan wawancara dengan subjek yang mengetahui dan memahami tentang makam Sibayak Lingga yang berada di bukit Ndaholi Desa Perbesi Kecamatan Tigabinanga, maka penulis merumuskan beberapa kesimpulan, yaitu sebagai beriku:

-Masyarakat Desa Perbesi merupakan masyarakat yang tidak lupa akan nenek moyangnya dan tradisi yang telah dilakukan secara turuntenurun. Adapun latar belakang masyarakat Perbesi menyembah ataupun membuat ritual kepada makam Sibayak Lingga dikarenakan sejarah dari Sibayak Lingga dan dari cerita masyarakat pada jaman dahulu. Selain itu masyarakat juga melihat bahwa Raja Sibayak Lingga dulunya memiliki kesaktian, maka dari itu sebagian dari masyarakat Desa Perbesi meyakini bahwasanya makam tersebut dapat memberikan suatu keinginan seperti meminta jodoh, meminta nomor (togel), menyembuhkan penyakit, dan membuang segala kesialan dengan berharap rejeki pun melimpah.

Adapun proses ritual yang dilakukan oleh masyarakat terhadap makam Sibayak Lingga adalah erpangir (mandi kembang), ngamburi lau simalemmalem (mandi air suci) dan mulahken manuk mbentar (melepaskan ayam yangberbulu putih). Adapun ritualritual yang dibuat oleh masyarakat karo yang berada di Desa Perbesi tersebut dipercaya oleh masyarakat perbesi seperti ritual mulahken manuk mbentar.

Menurut masyarakat Desa Perbesi sendiri ritual yang dilakukan masyarakat Desa perbesi adalah salah satu wujud kepedulian mereka terhadap makam Sibayak Lingga. Selain sebagai wujud kepedulian masyarakat perbesi ingin tradisi yang telah dibuat untuk makam Sibayak Lingga tidak terputus dan terus berlangsung setiap tahunnya. Selain itu jiarah yang dilakukan oleh masyarakat Perbesi adalah salah satu wujud 
membersihkan diri dan membuang segala kesialan dengan mengharapkan keberuntungan. Selain itu Menurut penulis dengan masuknya agama Desa Perbesi sangat berpengaru dalam tradisi-tradisi ritual yang berlangsung setiap tahunnya dan keseharian mereka terhadap Sibayak Lingga. Karena ada beberapa masyarakat tidak mengikuti lagi ritual-ritual yang dibuat pada makam Sibayak Lingga tersebut. Selain itu banyak dari ajaran agama yang bertentangan juga dengan beberapa tradisi yang dibuat oleh masyarakat pada umumnya.

\section{DAFTAR PUSTAKA}

Basrowo dan Suwandi. (2008). Memahami penelitian kualitatif. Jakarta: PT. Rineka Cipta.

Durkheim, Emile. (2003). Elementery Forms of The Religions Life. Penerbit: Irlisod.

Koentjaraningrat, Prof. Dr. (1985). Beberapa Pokok Antropologi Sosial. Jakarta: Dian rakyat.

Koentjaraningrat, Prof. Dr. (1980). Sejarah Antropologi I. Jakarta : Universitas Indonesia.

Lingga, Kerong (1971). Sejarah Sibayak Lingga Tanah Karo. Tigabinanga :

Nazir, mohamad. (2003). Metode penelitian. Jakarta: Ghalia Indonesia.

Radam, Noerid Haloei. (2001). Religi Orang Bukit. Yogyakarta: Yayasan semesta.

Sarwono, Jhonatan. (2006). Metode Penelitian Kuantitatif dan Kualitatif. Yogyakarta: Graha Ilmu.

Sugiyono. (2012). Metode Penelitian Kuantitatif Kualitatif dan $R \& D$. Bandung: Alberta

Van Baal, J. (1987). Sejarah Dan Pertumbuhan Teori Antropologi Budaya (Hingga Dekade 1970). Jakarta: PT Gramedia.

Muhadi, Muhamad (2009) Kepercayaan masyarakat terhadap sumur tua (studi diskriptif: di kelurahan tunggurono kecamatan binjai timur. FISIP-USU: Medan

Repandu (2014), Candiki Kajian Antropologis ritual ziarah kubur orang indonesia di kota qum dan kota masyhad,republik islam iran. FIS-UNIMED: Medan

Sembiring, Rosmiani (2014) kepercayaan masyarakat terhadap tempat keramat studi kasus daerah tamba kecamatan sitio-tio kabupaten samosir provinsi sumatra utara. FISIP-USU: Medan 